Research Article

\title{
Bioaugmentation with Mixed Hydrogen-Producing Acetogen Cultures Enhances Methane Production in Molasses Wastewater Treatment
}

\author{
Shuo Wang $\mathbb{D},{ }^{1,2,3}$ Jianzheng $\mathrm{Li}\left(\mathbb{D},{ }^{4}\right.$ Guochen Zheng, ${ }^{5}$ Guocheng $\mathrm{Du},{ }^{6}$ and Ji Li $\mathbb{D}^{1,2}$ \\ ${ }^{1}$ Jiangsu Key Laboratory of Anaerobic Biotechnology, School of Environment and Civil Engineering, Jiangnan University, \\ Wuxi 214122, China \\ ${ }^{2}$ Jiangsu College of Water Treatment Technology and Material Collaborative Innovation Center, Suzhou 215009, China \\ ${ }^{3}$ Department of Civil Engineering, University of Calgary, Calgary, AB, Canada T2N 1N4 \\ ${ }^{4}$ State Key Laboratory of Urban Water Resource and Environment, Harbin Institute of Technology, Harbin 150090, China \\ ${ }^{5}$ Songliao River Basin Administration of Water Resources Protection, Changchun 130021, China \\ ${ }^{6}$ Ministry Key Laboratory of Industrial Biotechnology, School of Biotechnology, Jiangnan University, Wuxi 214122, China
}

Correspondence should be addressed to Ji Li; liji@jiangnan.edu.cn

Received 1 May 2018; Accepted 9 July 2018; Published 1 August 2018

Academic Editor: Guangbin Li

Copyright (c) 2018 Shuo Wang et al. This is an open access article distributed under the Creative Commons Attribution License, which permits unrestricted use, distribution, and reproduction in any medium, provided the original work is properly cited.

\begin{abstract}
Hydrogen-producing acetogens (HPA) have a transitional role in anaerobic wastewater treatment. Thus, bioaugmentation with HPA cultures can enhance the chemical oxygen demand (COD) removal efficiency and $\mathrm{CH}_{4}$ yield of anaerobic wastewater treatment. Cultures with high degradation capacities for propionic acid and butyric acid were obtained through continuous subculture in enrichment medium and were designated as Z08 and Z12. Bioaugmentation with Z08 and $\mathrm{Z12}$ increased $\mathrm{CH}_{4}$ production by glucose removal to 1.58. Bioaugmentation with Z08 and Z12 increased the COD removal rate in molasses wastewater from $71.60 \%$ to $85.84 \%$. The specific $\mathrm{H}_{2}$ and $\mathrm{CH}_{4}$ yields from COD removal increased by factors of 1.54 and 1.63 , respectively. Results show that bioaugmentation with $\mathrm{HPA}$-dominated cultures can improve $\mathrm{CH}_{4}$ production from $\mathrm{COD}$ removal. Furthermore, hydrogen-producing acetogenesis was identified as the rate-limiting step in anaerobic wastewater treatment.
\end{abstract}

\section{Introduction}

High-strength organic wastewater and municipal sludge can be efficiently treated through anaerobic processes, which produce $\mathrm{CH}_{4}$ as the main product [1]. The microbial cultures used in anaerobic wastewater treatment are highly complex and include fermentative bacteria, hydrogen-producing acetogens (HPA), and methanogenic bacteria (MB) $[2,3]$. HPA species are applied in anaerobic wastewater treatment as an alternative to $\mathrm{MB}$, sulfate-reducing bacteria, and other hydrogen-consuming bacteria [4]. However, only a few strains of HPA have been isolated and purified because the species are obligate or facultative anaerobe. HPA mainly converts volatile fatty acids (VFAs) and ethanol into acetic acid, $\mathrm{H}_{2}$, and $\mathrm{CO}_{2}[5,6]$. The metabolic products of HPA, in turn, promote $\mathrm{CH}_{4}$ production by $\mathrm{MB}$ [7].
Propionate acid tends to accumulate in high-strength organic wastewater, and the COD removal efficiency from wastewater decreases with increasing influent COD [8]. Previous studies attributed this phenomenon to methanogenesis because MB has a slow growth rate, narrow ecological niche, and stringent requirements for living conditions $[9,10]$. In addition, VFA degradation is the rate-limiting step in anaerobic wastewater treatment because it is subject to the acetic acid degradation pathway and can decelerate and decrease acetic acid conversion $[10,11]$. The degradation of propionate and butyrate acids by HPA cannot proceed spontaneously under normal conditions because it requires energy consumption [6]. By contrast, the terminal product $\mathrm{CH}_{4}$ can be spontaneously produced under normal conditions when acetic acid, $\mathrm{H}_{2}$, and $\mathrm{CO}_{2}$ are present in sufficient amounts [6]. This phenomenon indicates that the substrate 
conversion capacity of MB is higher than that of HPA. Therefore, hydrogen-producing acetogenesis likely exerts considerable influence on the effectiveness of anaerobic wastewater treatment. The growth rate of HPA is as typically as slow as that of $\mathrm{MB}[12,13]$. HPA, however, requires more rigorous living conditions than MB [14]. Thus, HPA could potentially become the rate-limiting factor in anaerobic wastewater treatment under certain conditions.

HPA is a strictly anaerobic eubacteria, and most HPA species are mutualists $[15,16]$. The latter characteristic implies that the growth and metabolism of HPA completely depend on the presence of other microorganisms, such as methanogens [17]. McInerney and Bryant [4] and McInerney et al. [12] isolated four HPA strains that can degrade butyrate; comprehensively analyzed the growth, metabolism, phosphatidic acid composition, and nutrition of the isolates; and established the Syntrophomonadaceae family through $16 \mathrm{~S}$ rRNA sequencing analysis [18]. Medium-temperature propionic acid-oxidizing bacteria [19] have been recently obtained in fumarate culture medium. These bacteria exhibited remarkable activity in propionate oxidation associated with sulfate reduction. Syntrophobotulus glycolicus, Syntrophothermus lipocalidus, Sporomusa sphaeroides, and Moorella thermoacetica have been subsequently isolated [20-23]. However, given that pure HPA cultures are difficult to obtain, the ability of a HPA-dominated coculture of anaerobic microbes to enhance $\mathrm{CH}_{4}$ production and contaminant removal should be investigated $[10,24]$.

The effectiveness of anaerobic wastewater treatment depends mainly on the enrichment of functional microorganisms $[25,26]$. The performance of anaerobic wastewater treatment can be improved through bioaugmentation, which involves the addition of specific strains or dominated flora to the reaction system [27]. Bioaugmentation accelerates the start-up and maintains the stability of bioreactors and enhances the conversion rate of complex substrates. The methane production increased at least 38\% [26, 27] and has increased total biogas and $\mathrm{CH}_{4}$ yields through COD removal $[13,14]$. In addition, the ability of propionate-oxidizing and butyrate-oxidizing HPA to enhance $\mathrm{CH}_{4}$ production has been investigated.

In this work, cultures dominated by propionate-oxidizing and butyrate-oxidizing HPA were obtained from anaerobic sludge through enrichment culture. The organic substrate degradation capability of the propionate-oxidizing and butyrate-oxidizing microflora was investigated through batch cultures. The enhancement in $\mathrm{CH}_{4}$ production and COD removal rates by bioaugmentation with the mixed HPA culture was evaluated.

\section{Materials and Methods}

2.1. Seed Sludge and Enrichment Medium. The original anaerobic activated sludge used to screen for HPAdominated cultures was collected from an anaerobic baffled reactor [28]. The enrichment medium, micronutrient solution, and vitamin solution were prepared as described by Liu et al. [13] and Wang et al. [14]. $10 \mathrm{~mL}$ of anaerobic sludge sampled and inoculated to $300 \mathrm{~mL}$ serum bottles, and each bottle contained $100 \mathrm{~mL}$ propionic acid or butyric acid enrichment medium. The serum bottles were purged with nitrogen gas for $20 \mathrm{~min}$ and then cultivated under shaking at $130 \mathrm{r} / \mathrm{min}$ and $35^{\circ} \mathrm{C}$. Only when the consumption of propionic acid or butyric acid was up to $85 \%$ that $10 \mathrm{~mL}$ of bacterial suspension was extracted and injected as inocula for the subsequent batch cultures. The successful enrichment of HPA-dominated cultures (Z08 for HPA-dominated culture that oxidized propionic acid; Z12 for HPA-dominated culture that oxidized butyric acid) depended on the rate of $\mathrm{CH} 4$ production from propionic acid and butyric acid $[13,14]$.

2.2. Glucose and Molasses Wastewater. Glucose wastewater contained $5000 \mathrm{mg} / \mathrm{L}$ of glucose and was modified with $1000 \mathrm{mg} / \mathrm{L}$ of $\mathrm{NH}_{4} \mathrm{Cl}, 600 \mathrm{mg} / \mathrm{L}$ of $\mathrm{NaCl}, 200 \mathrm{mg} / \mathrm{L}$ of $\mathrm{FeCl}_{2}$, $300 \mathrm{mg} / \mathrm{L}$ of $\mathrm{KH}_{2} \mathrm{PO}_{4}$, and $300 \mathrm{mg} / \mathrm{L}$ of $\mathrm{K}_{2} \mathrm{HPO}_{4}$. The COD of molasses wastewater was $8000 \mathrm{mg} / \mathrm{L}$. To maintain the bioactivity of the anaerobic activated sludge, $\mathrm{NH}_{4} \mathrm{Cl}$ and $\mathrm{K}_{2} \mathrm{HPO}_{4}$ were added at a COD:N:P ratio of 500:8:1. $\mathrm{NaHCO}_{3}$ was used to adjust the initial $\mathrm{pH}$ value of the wastewater to $7.8-8.0$.

2.3. Bioaugmentation Batch Test. Bioaugmentation batch tests were conducted to evaluate the effect of HPAdominated microflora. Four serum bottles $(500 \mathrm{~mL})$ were used for glucose degradation. Each serum bottle contained $300 \mathrm{~mL}$ of glucose wastewater and $30 \mathrm{~mL}$ of anaerobic activated sludge. The original mixed liquor volatile suspended solids (MLVSS) of anaerobic sludge, Z08, and Z12 was $12400 \mathrm{mg} / \mathrm{L}, 2500 \mathrm{mg} / \mathrm{L}$, and $3600 \mathrm{mg} / \mathrm{L}$, respectively; in particular, the MLVSS of anaerobic sludge, Z08, and Z12 were uniformly diluted to $350 \mathrm{mg} / \mathrm{L}$ to maintain the initial MLVSS which was equal in each sample. Each serum bottle contained biomass at the rate of $40 \mathrm{mg}$ MLVSS/L. The experimental scheme for bioaugmented glucose wastewater treatment was designed as follows: FH1 $(30 \mathrm{~mL}$ of anaerobic activated sludge), FH2 (27 mL of anaerobic activated sludge and $3 \mathrm{~mL}$ of Z08), FH3 (26 mL of anaerobic activated sludge and $4 \mathrm{~mL}$ of $\mathrm{Z12}$ ), and FH4 (27 mL of anaerobic activated sludge, $1.8 \mathrm{~mL}$ of $\mathrm{Z} 08$, and $1.2 \mathrm{~mL}$ of $\mathrm{Z12}$ ). Four serum bottles $(500 \mathrm{~mL})$ were utilized for normal molasses wastewater treatment. Each serum bottle contained $240 \mathrm{~mL}$ of normal molasses wastewater and $40 \mathrm{~mL}$ of anaerobic activated sludge. Each serum bottle contained biomass in the form of MLVSS at the rate of $50 \mathrm{mg}$ MLVSS/L. The experimental scheme for bioaugmented molasses wastewater treatment was designed as follows: QJ1 (40 mL of anaerobic activated sludge), QJ2 (36 mL of anaerobic activated sludge and $4 \mathrm{~mL}$ of Z08), QJ3 (35 mL of anaerobic activated sludge and $5 \mathrm{~mL}$ of Z12), and QJ4 (36 mL of anaerobic activated sludge, $2.0 \mathrm{~mL}$ of $\mathrm{Z} 08$, and $2.0 \mathrm{~mL}$ of $\mathrm{Z12}$ ). All serum bottles were cultivated under shaking at $130 \mathrm{r} / \mathrm{min}$ and $35^{\circ} \mathrm{C}$.

2.4. Iodonitrotetrazolium Chloride-Dehydrogenase. Dehydrogenase is an organic macromolecule that is secreted by microorganisms. It is used as an index for the evaluation of the bioactivity of anaerobic activated sludge [29]. Iodonitrotetrazolium chloride (INT) has low redox potential $(+90 \mathrm{mV})$. This characteristic indicates that INT has high 


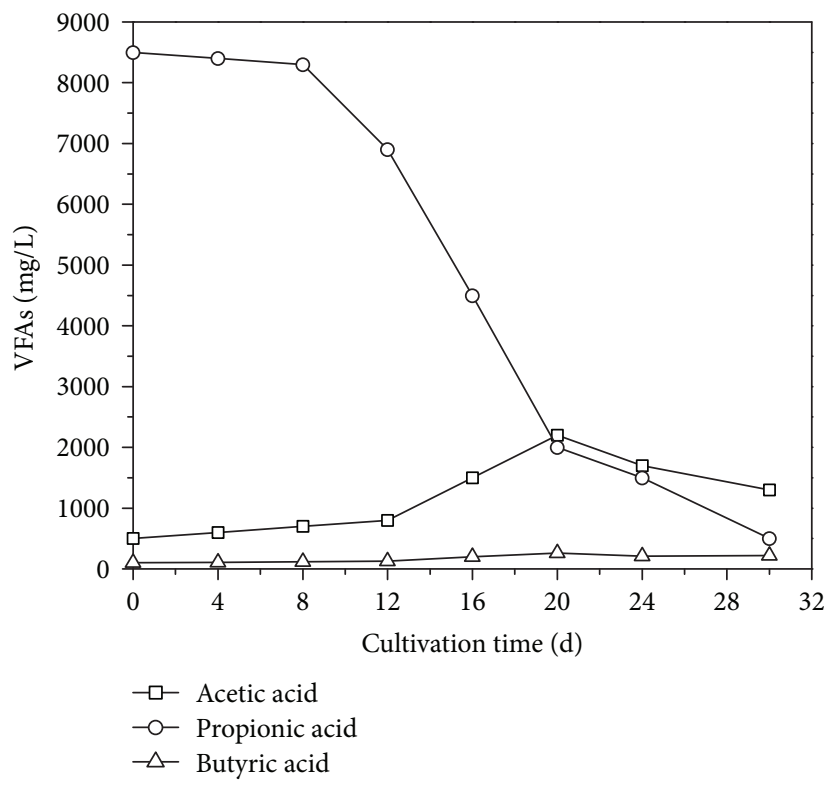

(a)

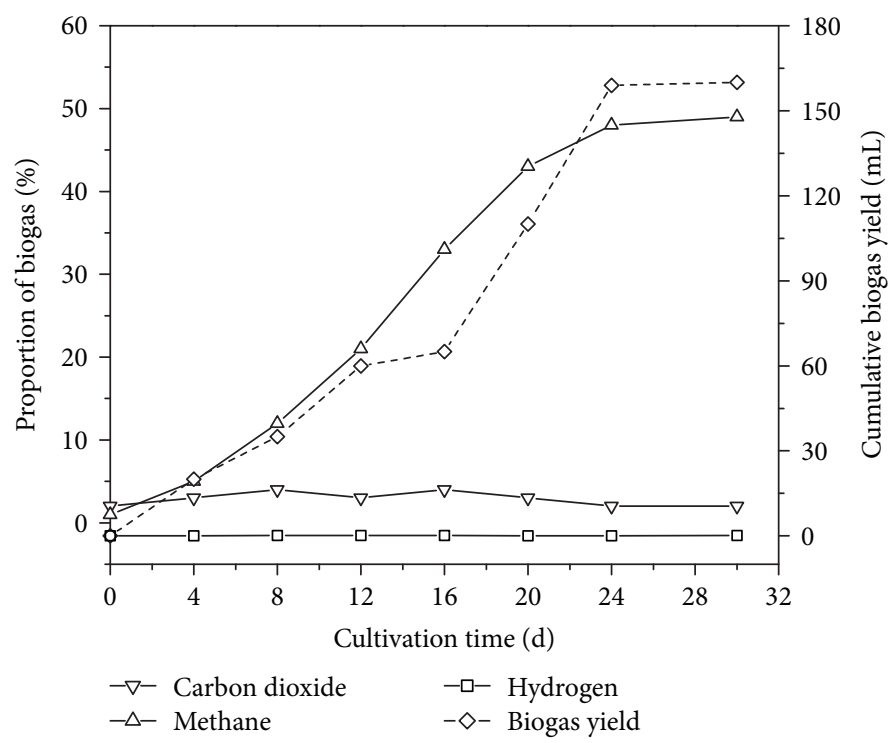

(b)

Figure 1: Performance of Z08 through propionic acid degradation (a) and methane production (b).

electron affinity [30] and suggests that dehydrogenase activity can be measured on the basis of INT activity. Dehydrogenase activity (UI) can be calculated using

$$
U I=15.15 \cdot \frac{A}{W},
$$

where UI is the dehydrogenase activity ( $\mu \mathrm{mol}$ INT/g.min), $A$ denotes the absorbance of the extract liquor, and $W$ represents biomass content (MLVSS, mg).

2.5. Analytical Methods. COD and MLVSS values were measured in accordance with standard methods [31]. Glucose was measured through the phenol-sulfuric acid method [32]. The biogas yield in each bottle was measured periodically using 5 and $50 \mathrm{~mL}$ syringes, and biogas constituents $\left(\mathrm{H}_{2}, \mathrm{CO}_{2}\right.$, and $\left.\mathrm{CH}_{4}\right)$ were characterized through gas chromatography (Lunan SC-7, China). The components of ethanol and VFAs (acetic acid, propionic acid, and butyric acid from the liquid phase of the reaction system) were analyzed through gas chromatography (AAC GC-112, China). The experiment was run in triplicate.

\section{Results and Discussion}

\subsection{Enrichment of HPA}

3.1.1. Propionate-Oxidizing HPA. Z08, a mixed culture dominated by propionate-oxidizing HPA, was successfully obtained after ten generations of continuous subculture. As listed in Supplementary Table 1, the acetic acid yield and accumulative $\mathrm{H}_{2}$ yield was $1007.9 \mathrm{mg} / \mathrm{L}$ and $49.2 \mathrm{~mL}$, respectively, indicating that the propionate-oxidizing HPA performed well in propionic acid degradation and supplied sufficient substances for methane production. The conversion rate of propionic acid was $18.5 \mathrm{mmol} / \mathrm{gMLVSS} \cdot \mathrm{d}$, and the rate of methane production from propionic acid was 0.49. As shown in Figure 1(a), bioaugmentation with Z08 rapidly decreased propionic acid concentration from $8436.71 \mathrm{mg} / \mathrm{L}$ to $8083.74 \mathrm{mg} / \mathrm{L}$ and increased acetic acid concentration from $524.61 \mathrm{mg}$ to $701.43 \mathrm{mg}$. This result indicates that Z08 has good adaptation performance. After 9 days of inoculation with Z08, propionic acid concentration significantly decreased from $8083.74 \mathrm{mg} / \mathrm{L}$ to $2008.91 \mathrm{mg} / \mathrm{L}$, whereas acetic acid concentration increased from $701.43 \mathrm{mg} / \mathrm{L}$ to $2251.49 \mathrm{mg} / \mathrm{L}$. The $\mathrm{H}_{2}$ and $\mathrm{CO}_{2}$ contents of the biogas increased from $0.06 \%$ to $0.09 \%$ and from $11.53 \%$ to $18.76 \%$ (Figure $1(\mathrm{~b})$ ), respectively, whereas $\mathrm{CH}_{4}$ content sharply increased to $45.42 \%$. However, the degradation of propionic acid slowed down and decreased to $351.14 \mathrm{mg} / \mathrm{L}$ after 30 days of subculture. The accumulated acetic acid concentration was $1203.53 \mathrm{mg} / \mathrm{L}$. The cumulative biogas yield was $161 \mathrm{~mL}$, and $\mathrm{H}_{2}, \mathrm{CH}_{4}$, and $\mathrm{CO}_{2}$ contents were $0.12 \%, 49.14 \%$, and $11.27 \%$, respectively. In addition, the terminal $\mathrm{pH}$ value of the entire reaction system stabilized at 7.30-7.40. This $\mathrm{pH}$ range is suitable for enhanced propionic acid removal and $\mathrm{CH}_{4}$ production [33]. The average degradation rate of propionic acid under bioaugmentation with Z08 was $269.5 \mathrm{mg} / \mathrm{L} \cdot \mathrm{d}$. The conversion rate of propionic acid was $22.1 \mathrm{mmol} / \mathrm{gMLVSS} \cdot \mathrm{d}$, and the rate of $\mathrm{CH}_{4}$ production from propionic acid was 0.41 .

Propionic acid degradation can be divided into three stages on the basis of two distinct turning points. The first stage is the adaptation stage and occurred from days 0 to 8 of degradation. During this stage, propionic acid degradation was low. The second stage occurred from days 9 to 20 of degradation. During this stage, the microorganisms in Z08 adapted to the new living conditions and actively degraded propionic acid. Most of propionic acid was consumed through the synergistic action of $\mathrm{MB}[13,34]$. The third stage occurred from days 21 to 30 of degradation. As the propionic 


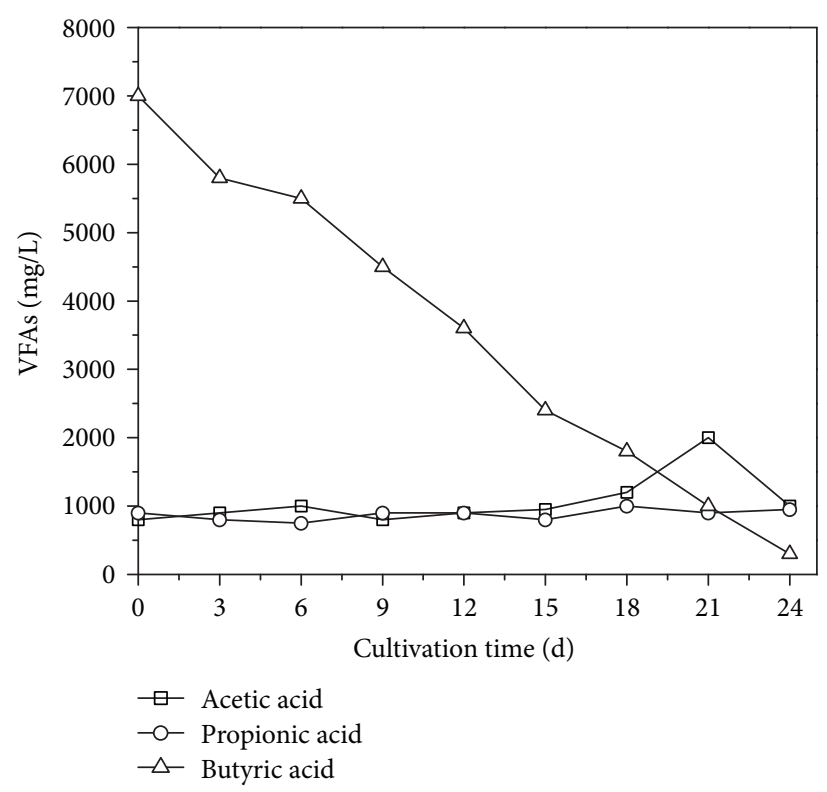

(a)

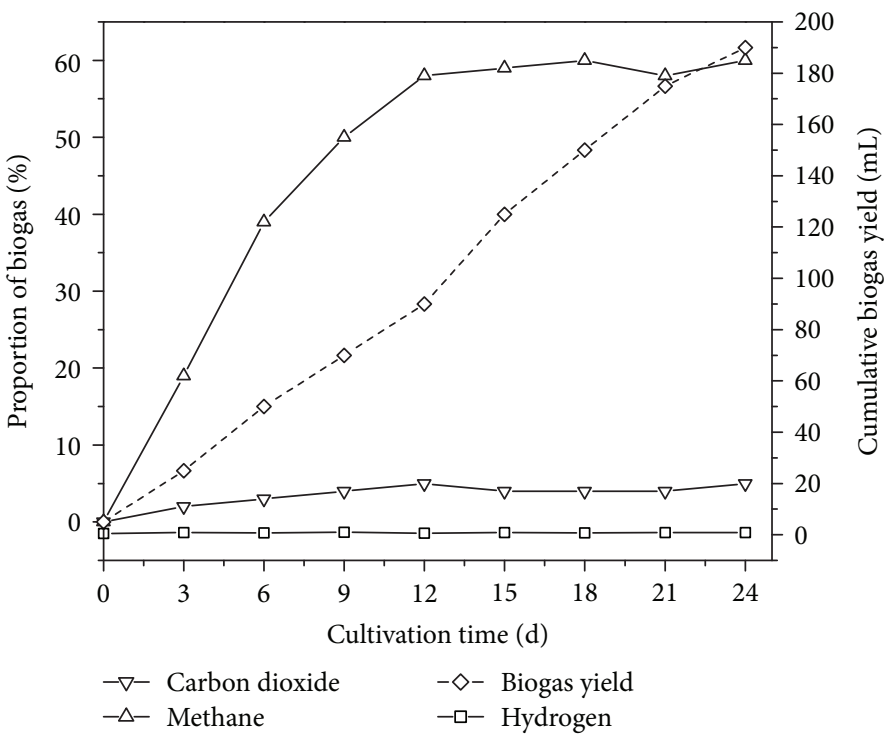

(b)

Figure 2: Performance of Z12 through butyric acid degradation (a) and methane production (b).

acid content of the culture medium decreased, microbial activity was reduced because the microorganisms in Z08 competed with one another. In addition, excessive acetic acid generation during stage 2 triggered feedback inhibition as shown by (2). Feedback inhibition then decelerated propionic acid degradation [35]. However, the bioactivity of MB in Z08 was not inhibited, and propionic acid concentration decreased again when acetic acid was converted to $\mathrm{CH}_{4}$ by $\mathrm{MB}$.

$$
\begin{aligned}
\mathrm{CH}_{3} \mathrm{CH}_{2} \mathrm{COOH} & +\mathrm{H}_{2} \mathrm{O} \longrightarrow 2 \mathrm{CH}_{3} \mathrm{COOH}+3 \mathrm{H}_{2} \\
& +\mathrm{CO}_{2} \triangle \mathrm{G}^{0 \prime}=+76.1 \mathrm{~kJ} / \mathrm{mol}
\end{aligned}
$$

3.1.2. Butyrate-Oxidizing HPA. Z12, a mixed culture dominated by butyrate-oxidizing HPA, was successfully obtained after seven generations of continuous subculture. As listed in Supplementary Table 2, the acetic acid yield and accumulative $\mathrm{H}_{2}$ yield was $900.7 \mathrm{mg} / \mathrm{L}$ and $51.6 \mathrm{~mL}$, respectively, indicating that the butyrate-oxidizing HPA presented good capacity in butyric acid degradation and provided sufficient substances for methane production. The conversion rate of butyric acid was $15.5 \mathrm{mmol} / \mathrm{gMLVSS} \cdot \mathrm{d}$, and the rate of methane production from butyric acid was 0.75 . As illustrated in Figure 2(a), over 3 days of inoculation with Z12, butyric acid concentration decreased from $7063.64 \mathrm{mg} / \mathrm{L}$ to $5727.3 \mathrm{mg} / \mathrm{L}$, and acetic acid concentration increased from $659.88 \mathrm{mg} / \mathrm{L}$ to $788.59 \mathrm{mg} / \mathrm{L}$. $\mathrm{H}_{2}, \mathrm{CH}_{4}$, and $\mathrm{CO}_{2}$ concentrations in biogas increased by $0.06 \%, 18.68 \%$, and $4.64 \%$ (Figure 2(b)), respectively, indicating that HPA in $\mathrm{Z} 12$ had begun to degrade butyric acid into acetic acid, $\mathrm{H}_{2}$, and $\mathrm{CO}_{2}$ to provide substrates for $\mathrm{MB}$ in $\mathrm{Z} 12$. However, butyric acid degradation slowed down from days 4 to 6 along with the treatment process, and butyric acid content remained at $5500 \mathrm{mg} / \mathrm{L}$. Subsequently, butyric acid concentration sharply decreased from $5457.28 \mathrm{mg} / \mathrm{L}$ to $776.29 \mathrm{mg} / \mathrm{L}$, and the cumulative acetic acid concentration peaked at $1762.43 \mathrm{mg} / \mathrm{L}$. The $\mathrm{H}_{2}$ content of the biogas peaked on day 9 , and $\mathrm{CH}_{4}$ and $\mathrm{CO}_{2}$ content also rapidly increased. Butyric acid concentration decreased to $211.83 \mathrm{mg} / \mathrm{L}$ on day 24 , whereas acetic acid concentration gradually decreased on day 21 . Moreover, the $\mathrm{H}_{2}$ content of the biogas also declined. The terminal concentrations of butyric acid and acetic acid were 211.83 and $827.65 \mathrm{mg} / \mathrm{L}$, respectively. The cumulative biogas yield was $191 \mathrm{~mL}$, and $\mathrm{CH}_{4}$ and $\mathrm{CO}_{2}$ contents reached as high as $60.76 \%$ and $16.45 \%$, respectively. The final $\mathrm{pH}$ value of the whole reaction system stabilized at 7.40-7.50, which is desirable for good butyric acid removal and $\mathrm{CH}_{4}$ production. The average degradation rate of butyric acid under bioaugmentation with $\mathrm{Z} 12$ was $285.5 \mathrm{mg} / \mathrm{L} \cdot \mathrm{d}$. The conversion rate of butyric acid was $15.8 \mathrm{mmol} / \mathrm{gMLVSS} \cdot \mathrm{d}$, and the rate of $\mathrm{CH}_{4}$ production from butyric acid was 0.74 .

Although the process of butyric acid degradation can also be divided into three phases, it differed from that of propionic acid degradation. Stage I, the acclimation period of Z12, occurred during days 1 to 3 of degradation and was shorter than the acclimation period of Z08. During this stage, Z12 rapidly degraded butyric acid, and acetic acid content increased. During stage II (days 4-6), the degradation rate of butyric acid declined (Figure 2(a)). In contrast to HPA, $\mathrm{MB}$ displayed good bioactivity in the reaction system because the methane production rate kept increasing during this stage. The slight accumulation of acetic acid indicated that hydrogenotrophic methanogen was dominant in $\mathrm{MB}$ and the community structure of $\mathrm{Z} 12$ thus facilitated $\mathrm{H} 2$ consumption, which further enhanced butyric acid degradation by HPA [36]. During stage III (days 7-24), HPA efficiently converted butyric acid to acetic acid and $\mathrm{H}_{2}$, and the acetic acid and $\mathrm{H}_{2}$ contents of the reaction system increased 
TABLE 1: Biogas yields and methane production performance of FH1 to FH4.

\begin{tabular}{|c|c|c|c|c|}
\hline & FH1 & $\mathrm{FH} 2$ & FH3 & FH4 \\
\hline Glucose conversion (\%) & 96 & 99 & 99 & 99 \\
\hline Biogas yield $(\mathrm{mL})$ & 140 & 198.9 & 205.7 & 259.9 \\
\hline Maximum specific methane production rate ( $\mathrm{mmol} / \mathrm{gMLVSS} \cdot \mathrm{d}$ ) & 0.89 & 1.27 & 1.56 & 2.26 \\
\hline Rate of methane production from glucose $(\mathrm{mol} / \mathrm{mol})$ & 1.32 & 1.60 & 1.79 & 2.32 \\
\hline Enhanced ratio of methane production (\%) & - & 125 & 224 & 262 \\
\hline
\end{tabular}

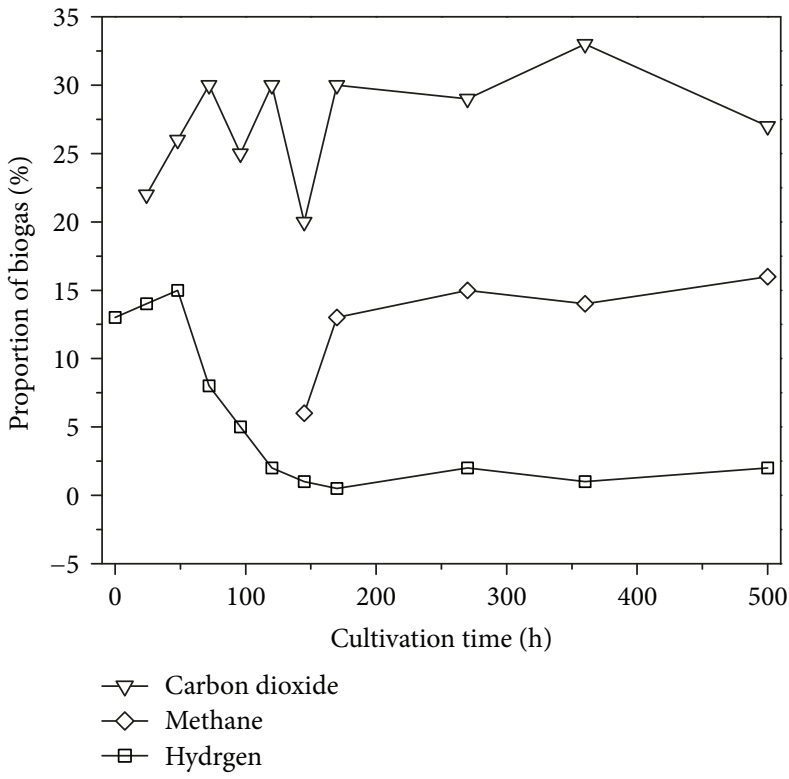

(a)

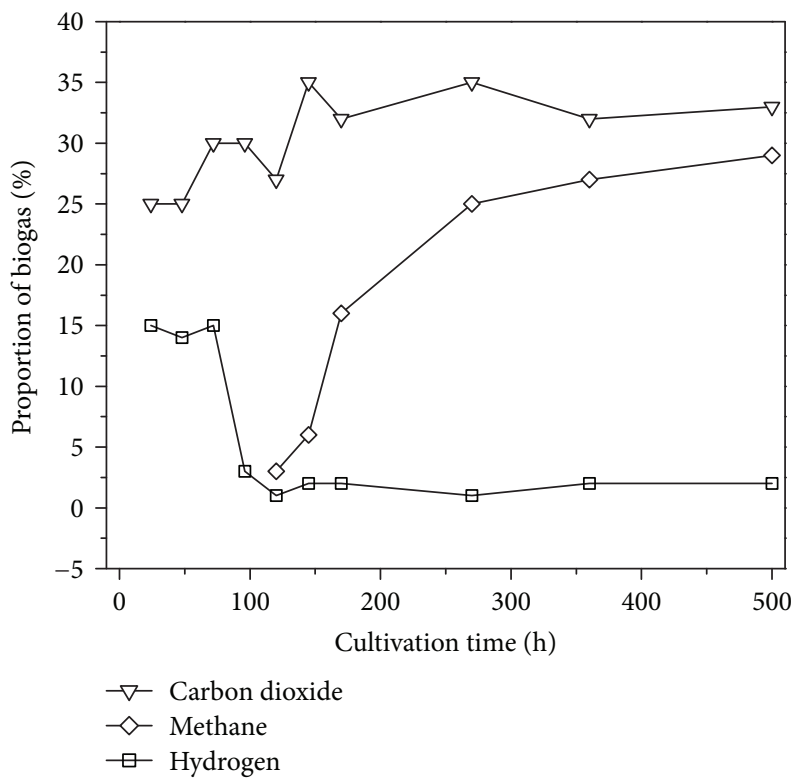

(c)

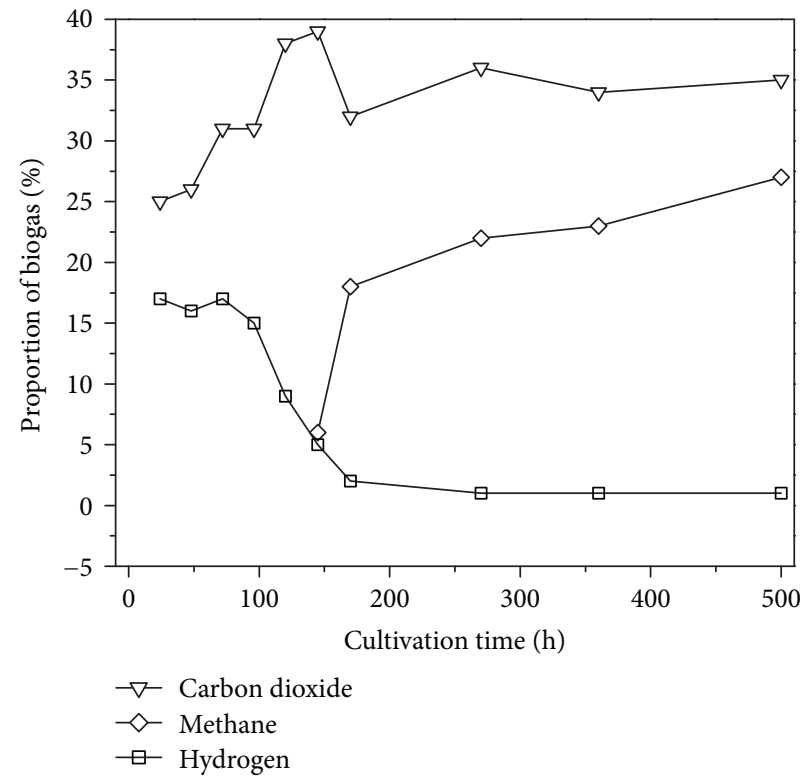

(b)

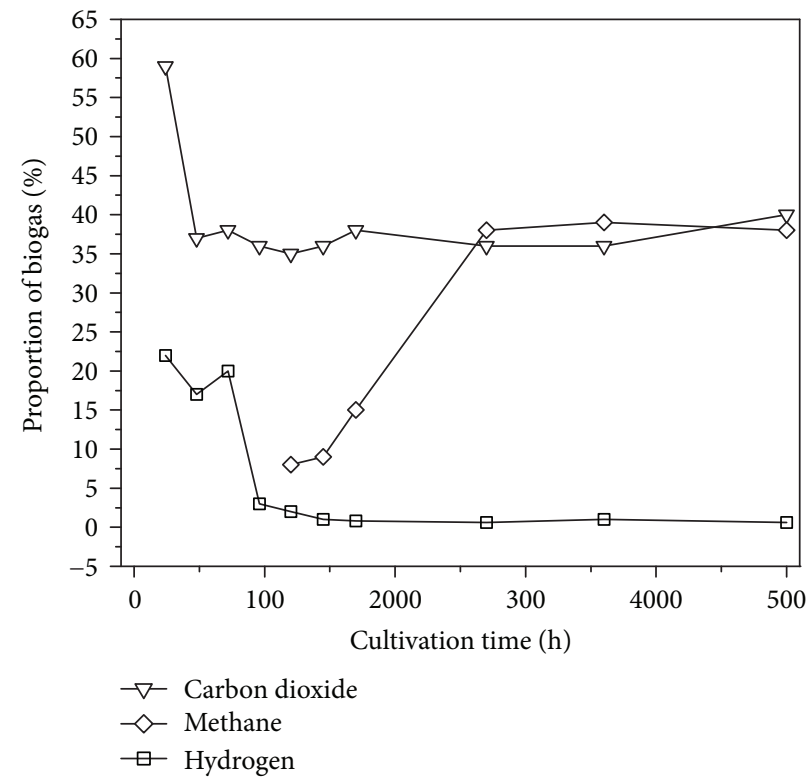

(d)

Figure 3: Biogas yields and component variation of QJ1 (a), QJ2 (b), QJ3 (c), and QJ4 (d).

temporarily (Figure 2(b)). By contrast, acetic acid concentration remained low because of the good substrate conversion efficiency of $\mathrm{MB}$.
3.1.3. Rate-Limiting Step of Anaerobic Wastewater Treatment. In general, acetic acid degradation by $\mathrm{MB}$ is an energyreducing reaction that can occur spontaneously under 


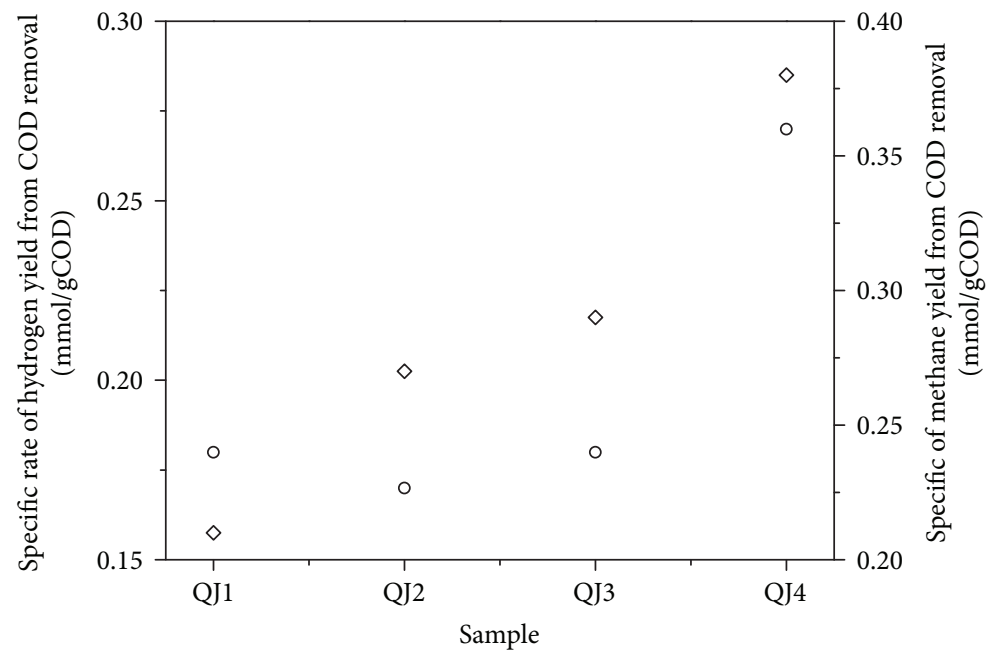

Specific rate of hydrogen yield from COD removal

$\diamond$ Specific rate of methane yield from COD removal

FIgURE 4: Specific hydrogen and methane production ratio by COD removal.

standard conditions. By contrast, as shown by (3), butyric acid degradation by HPA cannot occur spontaneously under standard conditions [35]. This behavior implies that the degradation of acetic acid by $\mathrm{MB}$ is easier than that of butyric acid by HPA.

$$
\begin{aligned}
\mathrm{CH}_{3} \mathrm{CH}_{2} \mathrm{CH}_{2} \mathrm{COOH} & +2 \mathrm{H}_{2} \mathrm{O} \longrightarrow 2 \mathrm{CH}_{3} \mathrm{CH}_{2} \mathrm{OH} \\
& +2 \mathrm{H}_{2} \triangle \mathrm{G}^{0 \prime}=+48.1
\end{aligned}
$$

Although hydrogenotrophic methanogens could not deplete $\mathrm{H}_{2}$ in time and decrease $\mathrm{pH}_{2}$, acetogenic methanogens converted acetic acid into $\mathrm{CH}_{4}$ in the culture medium [37]. Therefore, the reduction in acetic acid concentration could promote the degradation of butyric acid.

Similarly, propionate degradation by HPA cannot proceed spontaneously under normal conditions because this reaction requires energy consumption [6]. Nevertheless, propionic acid degradation could be enhanced by decreasing $\mathrm{H}_{2}$ concentration. Furthermore, propionic acid degradation requires a low system $\mathrm{pH}_{2}$ given its high standard Gibbsfree energy [38, 39]. In accordance with hydrogen partial pressure theory, propionic acid was rapidly degraded when $\mathrm{pH}_{2}$ was low, and propionic acid degradation slowed down when $\mathrm{H}_{2}$ accumulated (Figure 1).

Moreover, the acetic acid concentration of the culture medium was maintained at approximately $1000 \mathrm{mg} / \mathrm{L}$ throughout the reaction (Figures 1(a) and 2(a)) because of the presence of $\mathrm{MB}$, which could release feedback inhibition on propionic and butyric acid accumulation. Although the degradation of butyric acid in stage II was less and thus resulted in the accumulation of acetic acid (Figures 2(a) and 2(b)), methane production still increased, emphasizing that the rate-limiting step was not methanogenesis. The high $\mathrm{CH}_{4}$ yield implied the good bioactivity of $\mathrm{MB}$ and that the rate-limiting step of propionic acid and butyric acid degradation can be attributed to HPA $[8,40]$.
3.2. Performance of Mixed HPA Culture in Glucose Degradation. The biogas yield, maximum specific $\mathrm{CH}_{4}$ production rate, and $\mathrm{CH}_{4}$ production rate from glucose in $\mathrm{FH} 4$ were higher than those in FH1, FH2, and FH3 (Table 1). The contents of terminal VFAs (acetic acid, propionic acid, and butyric acid) in FH4 (139, 109, and $297 \mathrm{mg} / \mathrm{L})$ were markedly lower than those in FH3 (189, 149, and $433 \mathrm{mg} / \mathrm{L})$. These results indicated that the mixed HPA culture and the anaerobic activated sludge exhibit high glucose conversion rates. Bioaugmentation enhanced the rate of $\mathrm{CH}_{4}$ production from glucose, and the variation in $\mathrm{pH}$ corresponded to the variation in glucose degradation by the dominant microflora. The initial $\mathrm{pH}$ was maintained at 8.0. The acidification ratio reached $42.3 \%$ as glucose degradation proceeded [41], causing the $\mathrm{pH}$ value to decrease to 5.7. This $\mathrm{pH}$ value is unfavorable for $\mathrm{MB}$ [33]. Thereafter, the $\mathrm{pH}$ value recovered to 7.1 through the synergy of HPA and MB. This effect was particularly pronounced under high acetic acid conversion rates. The two types of dominant bacteria (Z08 and Z12) grew independently and performed specific microbial activities. The promoting effects of these activities on high-strength organic wastewater treatment require further study.

\subsection{Performance of Mixed HPA Culture in Normal Molasses Wastewater Treatment}

3.3.1. Biogas Components and Yields. As shown in Figure 3, the majority of the substrates in molasses wastewater were converted to $\mathrm{H}_{2}, \mathrm{CO}_{2}$, and $\mathrm{CH}_{4}$. These results indicate that bioaugmentation improves resource recovery. All reaction systems provided high $\mathrm{H}_{2}$ yields during the initial stages of treatment, and QJ4 provided the highest $\mathrm{H}_{2}$ yield $(23.76 \%)$ among all reaction systems. $\mathrm{H}_{2}$ content remained as high as $15 \%$ for the first $72 \mathrm{~h}$ of treatment and subsequently declined. By contrast, $\mathrm{CH}_{4}$ was not detected, indicating that homoacetogenic bacteria in the 


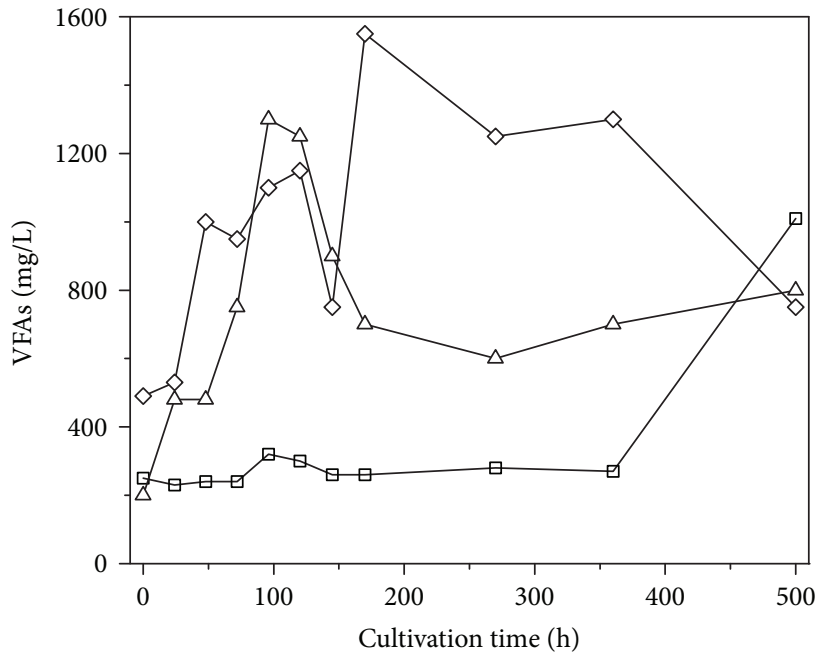

$$
\begin{aligned}
& \square \text { Acetic acid } \\
& \neg-\text { Propionic acid } \\
& \neg-\text { Butyric acid }
\end{aligned}
$$

(a)

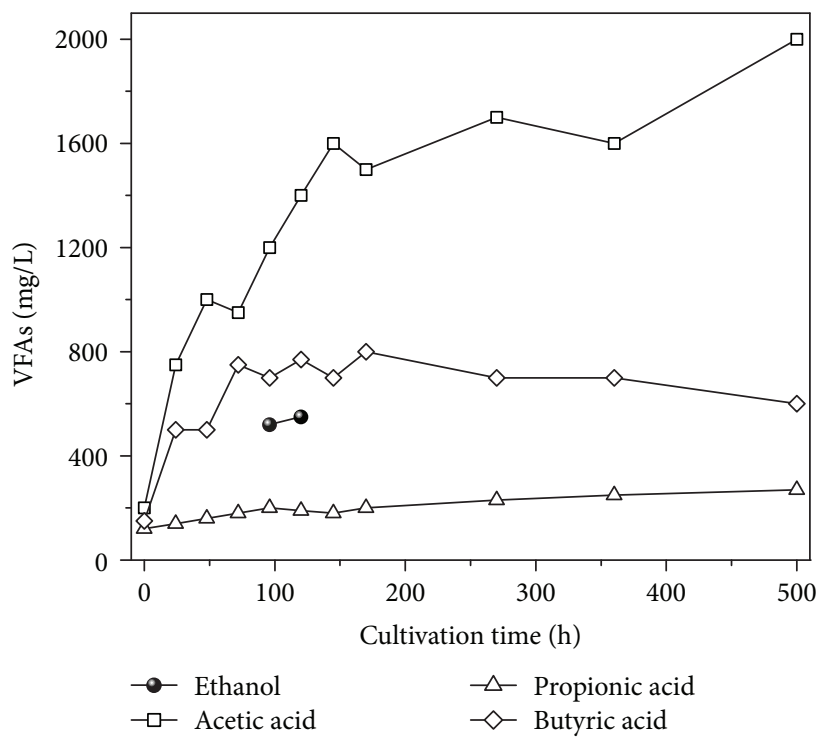

(c)

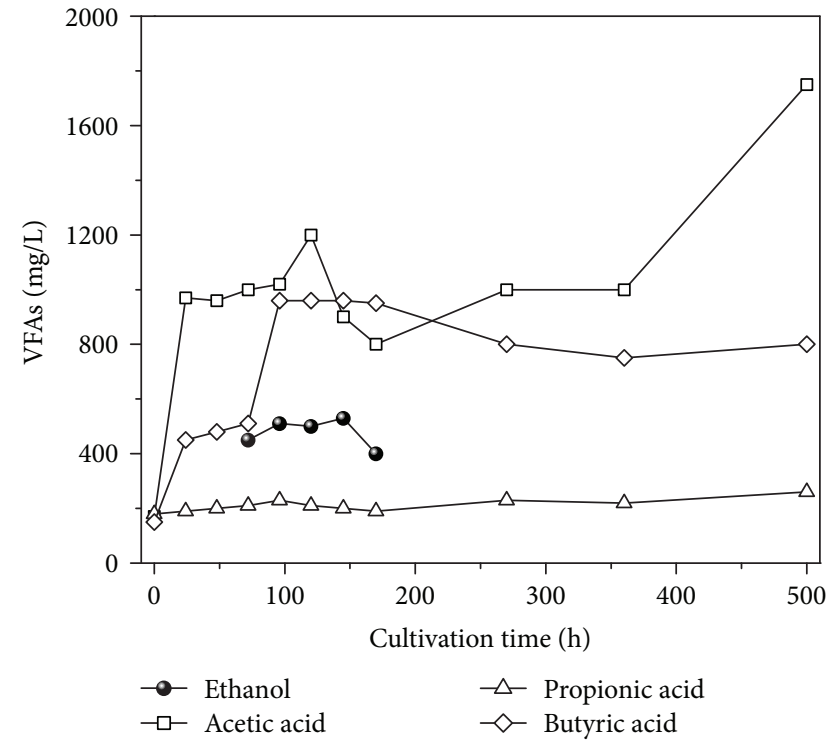

(b)

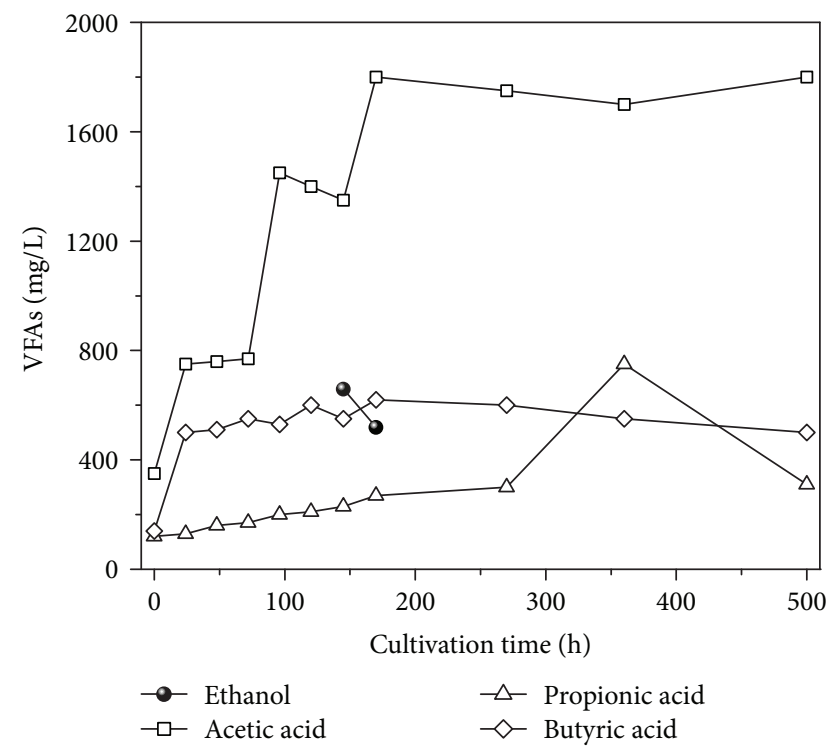

(d)

FIgURe 5: Terminal soluble products through normal molasses conversion of QJ1 (a), QJ2 (b), QJ3 (c), and QJ4 (d).

reaction system utilized $\mathrm{H}_{2}$ and $\mathrm{CO}_{2}$ to produce acetic acid [42]. $\mathrm{CH}_{4}$ was detected after $120 \mathrm{~h}$ in QJ3 and QJ4 and after $145 \mathrm{~h}$ in QJ1 and QJ2. These results imply that the bioactivity of the butyric-oxidizing HPA is higher than that of the propionic-oxidizing HPA [35]. The $\mathrm{CH}_{4}$ contents of the QJ2, QJ3, and QJ4 systems remained above $25 \%$ during acetogenesis, and the $\mathrm{CH}_{4}$ content of QJ4 reached as high as $37 \%$. However, the $\mathrm{CH}_{4}$ content of QJ1 was only approximately 15\% because HPA has low acetic acid, $\mathrm{H}_{2}$, and $\mathrm{CO}_{2}$ conversion capacities. The anaerobic activated sludge modified with the mixed HPA culture could produce sufficient substrates for $M B$ because ethanol, propionic acid, and butyric acid, as indicated by the quick and efficient conversion of the substrates into acetic acid, $\mathrm{H}_{2}$, and $\mathrm{CO}_{2}$.
The biogas yields of QJ2, QJ3, and QJ4 were 183, 226, and $252 \mathrm{~mL}$, respectively, and were moderately higher than that of QJ1. The cumulative $\mathrm{H}_{2}$ yields of QJ1, QJ2, QJ3, and QJ4 were $48.93,51.21,56.27$, and $89.43 \mathrm{~mL}$, respectively. The cumulative $\mathrm{CH}_{4}$ yields of QJ1, QJ2, QJ3, and QJ4 were $32.33,45.97,49.14$, and $61.91 \mathrm{~mL}$, respectively. These results collectively imply that HPA bioaugmentation increases $\mathrm{H}_{2}$ and $\mathrm{CH}_{4}$ production and improves molasses conversion. As shown in Figure 4, the specific rates of $\mathrm{H}_{2}$ and $\mathrm{CH}_{4}$ yields from COD removal under bioaugmentation with the mixed HPA culture in QJ4 had increased by a factor of 1.54 and 1.63 compared with those in QJ1. The experimental results show that bioaugmentation has a detectable effect and that it can effectively improve the efficiency of anaerobic wastewater treatment. 
TABLE 2: Correlation of specific dehydrogenase activity and COD removal.

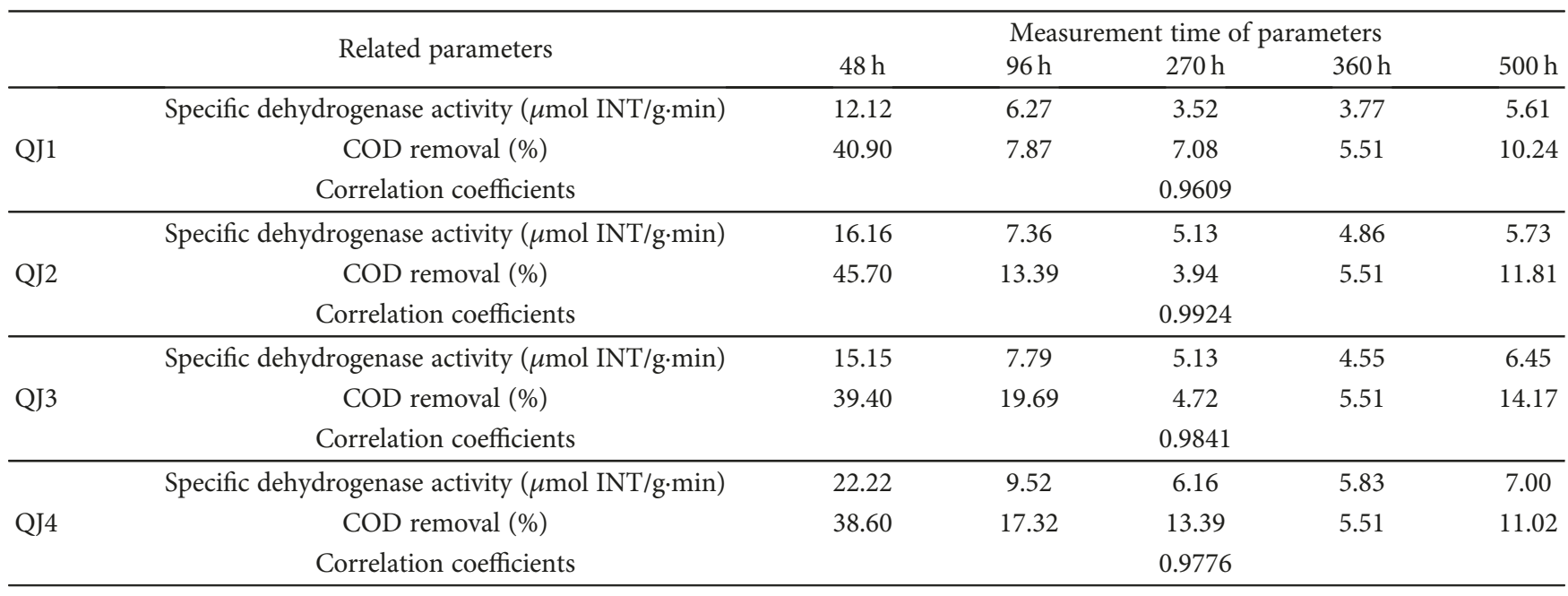

3.3.2. Terminal Soluble Products. As illustrated in Figure 5, the degradation of molasses wastewater by anaerobic activated sludge and HPA was inconsistent with that of glucose wastewater. Ethanol could be detected after $6 \mathrm{~h}$ of glucose degradation and after $72 \mathrm{~h}$ of molasses degradation. These results indicate that the mixed HPA culture can effectively convert ethanol into acetic acid, $\mathrm{H}_{2}$, and $\mathrm{CO}_{2}$ [43]. In addition, ethanol was not detected in QJ, suggesting that bioaugmentation with Z08 and Z12 promotes ethanol conversion from molasses and thereby decreases the possibility of propionic acid and butyric acid conversion from molasses. The conversion of ethanol into acetic acid is a spontaneous reaction [35]. Therefore, the substrate conversion rate increased in QJ2, QJ3, and QJ4 under relatively high ethanol content $(500 \mathrm{mg} / \mathrm{L})$. HPAdominated microflora has a transitional role in anaerobic wastewater treatment [34, 44], thus enhancing resource recovery (Figure 4).

In QJ1, no characteristics of VFA degradation were observed, and the terminal acetic acid, propionic acid, and butyric acid contents were 1000,780 , and $770 \mathrm{mg} / \mathrm{L}$, respectively, after $500 \mathrm{~h}$ of degradation. By contrast, in QJ2, QJ3, and QJ4, propionic and butyric acid degradation showed clear trends and improved as acetic acid content increased. The terminal acetic acid, propionic acid, and butyric acid contents were 1751, 230, and $847 \mathrm{mg} / \mathrm{L}$ in QJ2, respectively; 2047, 220, and $590 \mathrm{mg} / \mathrm{L}$ in QJ3, respectively; and 1841, 375 , and $580 \mathrm{mg} / \mathrm{L}$ in QJ4, respectively. The propionic acid and butyric acid contents in QJ2, QJ3, and QJ4 were significantly lower than those in QJ1 because propionic acid and butyric acid could be effectively degraded by the HPAdominated culture, and microbial metabolic products could be utilized by MB. Moreover, at $72-120 \mathrm{~h}$ of the reaction, acetic acid content considerably increased, $\mathrm{H}_{2}$ content decreased, and $\mathrm{CH}_{4}$ was not detected in QJ4 (Figures 3(d) and 5(d)). These results imply that homoacetogenesis has occurred in the reaction system. The initial $\mathrm{pH}$ value of the reaction system was 8.10 , which then sharply decreased to 4.50 within the first $48 \mathrm{~h}$ of the reaction because a large amount of VFAs were produced through acidogenesis [6, 41]. Correspondingly, $\mathrm{H}_{2}$ conversion increased. Thereafter, given the synergism of HPA and $\mathrm{MB}$, propionic acid, butyric acid, acetic acid, $\mathrm{H}_{2}$, and $\mathrm{CO}_{2}$ were successively utilized, and the $\mathrm{pH}$ value of the reaction system was maintained at approximately 7.00 .

3.3.3. Correlation of Specific Dehydrogenase Activity and COD Removal. The COD removal efficiencies in QJ1, QJ2, QJ3, and QJ4 were 71.7\%, 80.3\%, 83.5\%, and 85.8\%, respectively, after $500 \mathrm{~h}$ of anaerobic treatment. In QJ4, bioaugmentation with the mixed HPA culture increased substrate degradation and $\mathrm{CH}_{4}$ production. In addition, specific dehydrogenase activity was measured on the basis of INT throughout the process of molasses wastewater treatment. The specific dehydrogenase activity in QJ4 was significantly higher than that in $\mathrm{QJ} 1$, indicating that bioaugmentation with Z08 and Z12 improves microbial activity. The correlation coefficients between specific dehydrogenase activity and COD removal in the four systems were 0.9609, 0.9924, 0.9841 , and 0.9776 , as calculated by the CORREL function (Table 2). The experimental results demonstrate that the INT-specific dehydrogenase activity of anaerobic activated sludge is highly correlated with COD removal rate. Thus, the bioactivity of anaerobic activated sludge can be objectively and accurately reflected by INT-specific dehydrogenase activity [45].

\section{Conclusion}

Mixed cultures dominated by propionic- and butyricoxidizing HPA were obtained through more than seven generations of continuous subculture. The rate of $\mathrm{CH}_{4}$ production from propionic acid and butyric acid were 0.41 and 0.74 , respectively. Hydrogen-producing acetogenesis was identified as the rate-limiting factor of anaerobic wastewater treatment. Inoculation with the mixed cultures of Z08 and Z12 increased the biogas yield, maximum specific $\mathrm{CH}_{4}$ production rate, and $\mathrm{CH}_{4}$ production rate of glucose and molasses wastewater treatment, as well as increased the 
specific rates of $\mathrm{H}_{2}$ and $\mathrm{CH}_{4}$ yield from COD removal by a factor of 1.54 and 1.63, respectively. The INT-specific dehydrogenase activity of anaerobic activated sludge was highly correlated with COD removal efficiency.

\section{Data Availability}

The data used to support the findings of this study are available from the corresponding author upon request.

\section{Conflicts of Interest}

The authors declare that they have no conflicts of interest.

\section{Acknowledgments}

The study was supported by the National Natural Science Foundation of China (Grant no. 51478141), the Major Science and Technology Program for Water Pollution Control and Treatment (2017ZX07201-001), the State Key Laboratory of Urban Water Resource and Environment, Harbin Institute of Technology (Grant no. 2016DX06), and the Fundamental Research Funds for the Central Universities (Grant no. JUSRP51512).

\section{Supplementary Materials}

Table S1: metabolic characteristics of the subcultured microflora that oxidize propionic acid. Table S2: metabolic characteristics of the subcultured microflora that oxidize butyric acid. (Supplementary Materials)

\section{References}

[1] A. T. W. M. Hendriks, J. B. van Lier, and M. K. de Kreuk, "Growth media in anaerobic fermentative processes: the underestimated potential of thermophilic fermentation and anaerobic digestion," Biotechnology Advances, vol. 36, no. 1, pp. 1-13, 2018.

[2] P. Antwi, J. Li, P. Opoku Boadi et al., "Functional bacterial and archaeal diversity revealed by $16 \mathrm{~S}$ rRNA gene pyrosequencing during potato starch processing wastewater treatment in an UASB," Bioresource Technology, vol. 235, pp. 348-357, 2017.

[3] C. S. He, P. P. He, H. Y. Yang et al., "Impact of zero-valent iron nanoparticles on the activity of anaerobic granular sludge: from macroscopic to microcosmic investigation," Water Research, vol. 127, pp. 32-40, 2017.

[4] M. J. McInerney and M. P. Bryant, “Anaerobic degradation of lactate by syntrophic associations of Methanosarcina barkeri and Desulfovibrio species and effect of $\mathrm{H}_{2}$ on acetate degradation," Applied and Environmental Microbiology, vol. 41, no. 2, pp. 346-354, 1981.

[5] I. Valdez-Vazquez, A. L. Morales, and A. E. Escalante, "History of adaptation determines short-term shifts in performance and community structure of hydrogen-producing microbial communities degrading wheat straw," Microbial Biotechnology, vol. 10, no. 6, pp. 1569-1580, 2017.

[6] J. Li, G. Zheng, J. He, S. Chang, and Z. Qin, "Hydrogenproducing capability of anaerobic activated sludge in three types of fermentations in a continuous stirred-tank reactor," Biotechnology Advances, vol. 27, no. 5, pp. 573-577, 2009.
[7] Z. Zhang, P. Gao, J. Cheng, G. Liu, X. Zhang, and Y. Feng, "Enhancing anaerobic digestion and methane production of tetracycline wastewater in EGSB reactor with GAC/NZVI mediator," Water Research, vol. 136, pp. 54-63, 2018.

[8] L. Wang, Q. Zhou, and F. Li, "Avoiding propionic acid accumulation in the anaerobic process for biohydrogen production," Biomass and Bioenergy, vol. 30, no. 2, pp. 177-182, 2006.

[9] C. Y. Lin, K. Sato, T. Noike, and J. Matsumoto, "Methanogenic digestion using mixed substrate of acetic, propionic and butyric acids," Water Research, vol. 20, no. 3, pp. 385-394, 1986.

[10] M. Lange and B. K. Ahring, "A comprehensive study into the molecular methodology and molecular biology of methanogenic Archaea," FEMS Microbiology Reviews, vol. 25, no. 5, pp. 553-571, 2001.

[11] J. L. Garcia, B. K. C. Patel, and B. Ollivier, "Taxonomic, phylogenetic, and ecological diversity of methanogenic Archaea," Anaerobe, vol. 6, no. 4, pp. 205-226, 2000.

[12] M. J. McInerney, M. P. Bryant, and N. Pfennig, "Anaerobic bacterium that degrades fatty acids in syntrophic association with methanogens," Archives of Microbiology, vol. 122, no. 2, pp. 129-135, 1979.

[13] C. Liu, J. Li, S. Wang, and L. Nies, "A syntrophic propionateoxidizing microflora and its bioaugmentation on anaerobic wastewater treatment for enhancing methane production and COD removal," Frontiers of Environmental Science \& Engineering, vol. 10, no. 4, 2016.

[14] S. Wang, J. Li, C. Liu, L. Nies, and J. Li, "Enhanced methane production through bioaugmentation of butyrate-oxidizing hydrogen-producing acetogens in anaerobic wastewater treatment," Environmental Progress \& Sustainable Energy, vol. 37, no. 1, pp. 367-374, 2018.

[15] M. P. Bryant, E. A. Wolin, M. J. Wolin, and R. S. Wolfe, "Methanobacillus omelianskii, a symbiotic association of two species of bacteria," Archiv für Mikrobiologie, vol. 59, no. 1-3, pp. 20-31, 1967.

[16] J. Luo, Y. Chen, and L. Feng, "Polycyclic aromatic hydrocarbon affects acetic acid production during anaerobic fermentation of waste activated sludge by altering activity and viability of acetogen," Environmental Science \& Technology, vol. 50, no. 13, pp. 6921-6929, 2016.

[17] H. Junicke, H. Feldman, M. C. M. van Loosdrecht, and R. Kleerebezem, "Limitation of syntrophic coculture growth by the acetogen," Biotechnology and Bioengineering, vol. 113, no. 3, pp. 560-567, 2016.

[18] H. Zhao, D. Yang, C. R. Woese, and M. P. Bryant, “Assignment of fatty acid- $\beta$-oxidizing syntrophic bacteria to Syntrophomonadaceae fam. nov. on the basis of 16s rRNA sequence analyses," International Journal of Systematic Bacteriology, vol. 43, no. 3, 1993.

[19] A. J. Stams, J. Van Dijk, C. Dijkema, and C. M. Plugge, "Growth of syntrophic propionate-oxidizing bacteria with fumarate in the absence of methanogenic bacteria," Applied and Environmental Microbiology, vol. 59, no. 4, pp. 11141119, 1993.

[20] M. Friedrich, N. Springer, W. Ludwig, and B. Schink, "Phylogenetic positions of Desulfofustis glycolicus gen. nov., sp. nov. and Syntrophobotulus glycolicus gen. nov., sp. nov., two new strict anaerobes growing with glycolic acid," International Journal of Systematic Bacteriology, vol. 46, no. 4, pp. 10651069, 1996. 
[21] Y. Sekiguchi, Y. Kamagata, K. Nakamura, A. Ohashi, and H. Harada, "Syntrophothermus lipocalidus gen. nov., sp. nov., a novel thermophilic, syntrophic, fatty-acid-oxidizing anaerobe which utilizes isobutyrate," International Journal of Systematic and Evolutionary Microbiology, vol. 50, no. 2, pp. 771-779, 2000.

[22] S. Kato, I. Yumoto, and Y. Kamagata, "Isolation of acetogenic bacteria that induce biocorrosion by utilizing metallic iron as the sole electron donor," Applied and Environmental Microbiology, vol. 81, no. 1, pp. 67-73, 2015.

[23] A. Kita, Y. Iwasaki, S. Yano, Y. Nakashimada, T. Hoshino, and K. Murakami, "Isolation of thermophilic acetogens and transformation of them with the pyrF and $\mathrm{kan}^{r}$ genes," Bioscience, Biotechnology, and Biochemistry, vol. 77, no. 2, pp. 301-306, 2013.

[24] J. Li, B. Li, G. Zhu, N. Ren, L. Bo, and J. He, "Hydrogen production from diluted molasses by anaerobic hydrogen producing bacteria in an anaerobic baffled reactor (ABR)," International Journal of Hydrogen Energy, vol. 32, no. 15, pp. 3274-3283, 2007.

[25] G. Llorens-Blanch, E. Parlade, M. Martinez-Alonso, N. Gaju, G. Caminal, and P. Blanquez, "A comparison between biostimulation and bioaugmentation in a solid treatment of anaerobic sludge: drug content and microbial evaluation," Waste Management, vol. 72, pp. 206-217, 2018.

[26] B. E. Öner, Ç. Akyol, M. Bozan, O. Ince, S. Aydin, and B. Ince, "Bioaugmentation with Clostridium thermocellum to enhance the anaerobic biodegradation of lignocellulosic agricultural residues," Bioresource Technology, vol. 249, pp. 620-625, 2018.

[27] S. Aydin, "Enhancement of microbial diversity and methane yield by bacterial bioaugmentation through the anaerobic digestion of Haematococcus pluvialis," Applied Microbiology and Biotechnology, vol. 100, no. 12, pp. 5631-5637, 2016.

[28] G. F. Zhu, J. Z. Li, P. Wu, H. Z. Jin, and Z. Wang, "The performance and phase separated characteristics of an anaerobic baffled reactor treating soybean protein processing wastewater," Bioresource Technology, vol. 99, no. 17, pp. 8027-8033, 2008.

[29] C. Debnar-Daumler, A. Seubert, G. Schmitt, and J. Heider, "Simultaneous involvement of a tungsten-containing aldehyde:ferredoxin oxidoreductase and a phenylacetaldehyde dehydrogenase in anaerobic phenylalanine metabolism," Journal of Bacteriology, vol. 196, no. 2, pp. 483-492, 2014.

[30] W. von mersi and F. Schinner, "An improved and accurate method for determining the dehydrogenase-activity of soils with iodonitrotetrazolium chloride," Biology and Fertility of Soils, vol. 11, no. 3, pp. 216-220, 1991.

[31] APHA, Standard Methods for the Examination of Water and Wastewater, American Public Health Association, American Water Works Association, Water Environmental Federation, Washington, DC, USA, 21st edition, 2005.

[32] M. Dubois, K. A. Gilles, J. K. Hamilton, P. A. Rebers, and F. Smith, "Colorimetric method for determination of sugars and related substances," Analytical Chemistry, vol. 28, no. 3, pp. 350-356, 1956.

[33] M. S. Barredo and L. M. Evison, "Effect of propionate toxicity on methanogen-enriched sludge, Methanobrevibacter smithii, and Methanospirillum hungatii at different $\mathrm{pH}$ values," Applied and Environmental Microbiology, vol. 57, no. 6, pp. 1764-1769, 1991.

[34] G. Zheng, J. Li, F. Zhao et al., "Effect of illumination on the hydrogen-production capability of anaerobic activated sludge," Frontiers of Environmental Science \& Engineering, vol. 6, no. 1, pp. 125-130, 2012.

[35] Y. Liu and W. B. Whitman, "Metabolic, phylogenetic, and ecological diversity of the methanogenic archaea," Annals of the New York Academy of Sciences, vol. 1125, no. 1, pp. 171189, 2008 .

[36] T. Amani, M. Nosrati, and S. M. Mousavi, "Using enriched cultures for elevation of anaerobic syntrophic interactions between acetogens and methanogens in a high-load continuous digester," Bioresource Technology, vol. 102, no. 4, pp. 3716-3723, 2011.

[37] F. Chaucheyras, G. Fonty, G. Bertin, and P. Gouet, "In vitro H2 utilization by a ruminal acetogenic bacterium cultivated alone or in association with an archaea methanogen is stimulated by a probiotic strain of saccharomyces cerevisiae," Applied and Environmental Microbiology, vol. 61, no. 9, pp. 3466-3467, 1995.

[38] S. de Kok, J. Meijer, M. C. M. van Loosdrecht, and R. Kleerebezem, "Impact of dissolved hydrogen partial pressure on mixed culture fermentations," Applied Microbiology and Biotechnology, vol. 97, no. 6, pp. 2617-2625, 2013.

[39] O. Sarkar, S. K. Butti, and S. Venkata Mohan, "Acidogenesis driven by hydrogen partial pressure towards bioethanol production through fatty acids reduction," Energy, vol. 118, pp. 425-434, 2017.

[40] C. Gallert and J. Winter, "Propionic acid accumulation and degradation during restart of a full-scale anaerobic biowaste digester," Bioresource Technology, vol. 99, no. 1, pp. 170-178, 2008.

[41] H. H. P. Fang and H. Yu, "Mesophilic acidification of gelatinaceous wastewater," Journal of Biotechnology, vol. 93, no. 2, pp. 99-108, 2002.

[42] C. Liu, J. Li, Y. Zhang et al., "Influence of glucose fermentation on $\mathrm{CO}_{2}$ assimilation to acetate in homoacetogen Blautia coccoides GA-1," Journal of Industrial Microbiology \& Biotechnology, vol. 42, no. 9, pp. 1217-1224, 2015.

[43] X. Yang, K. Wang, H. Wang, J. Zhang, L. Tang, and Z. Mao, "Control of $\mathrm{pH}$ by acetic acid and its effect on ethanol fermentation in an integrated ethanol-methane fermentation process," RSC Advances, vol. 6, no. 63, pp. 57902-57909, 2016.

[44] H. Rajhi, D. Puyol, M. C. Martinez, E. E. Diaz, and J. L. Sanz, "Vacuum promotes metabolic shifts and increases biogenic hydrogen production in dark fermentation systems," Frontiers of Environmental Science \& Engineering, vol. 10, no. 3, pp. 513-521, 2016.

[45] J. K. Friedel, K. Mölter, and W. R. Fischer, "Comparison and improvement of methods for determining soil dehydrogenase activity by using triphenyltetrazolium chloride and iodonitrotetrazolium chloride," Biology and Fertility of Soils, vol. 18, no. 4, pp. 291-296, 1994. 


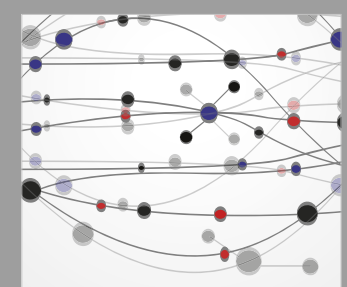

The Scientific World Journal
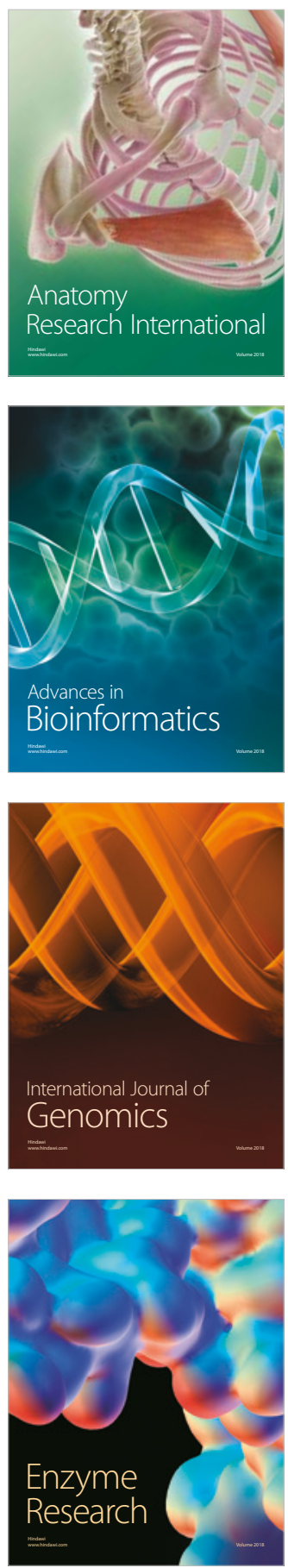
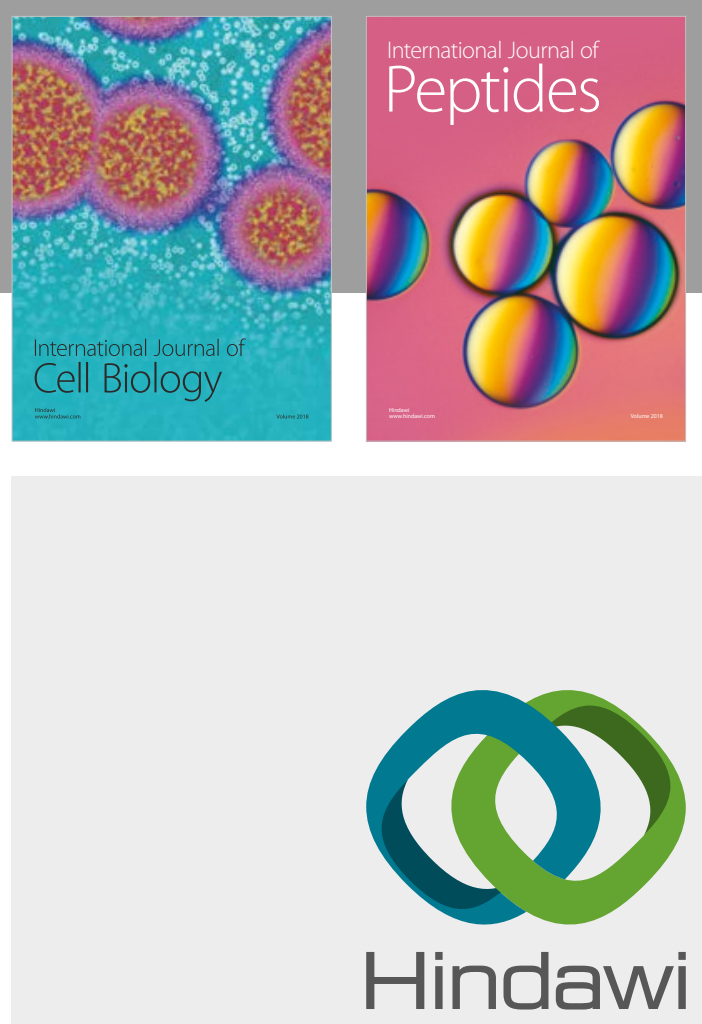

Submit your manuscripts at

www.hindawi.com
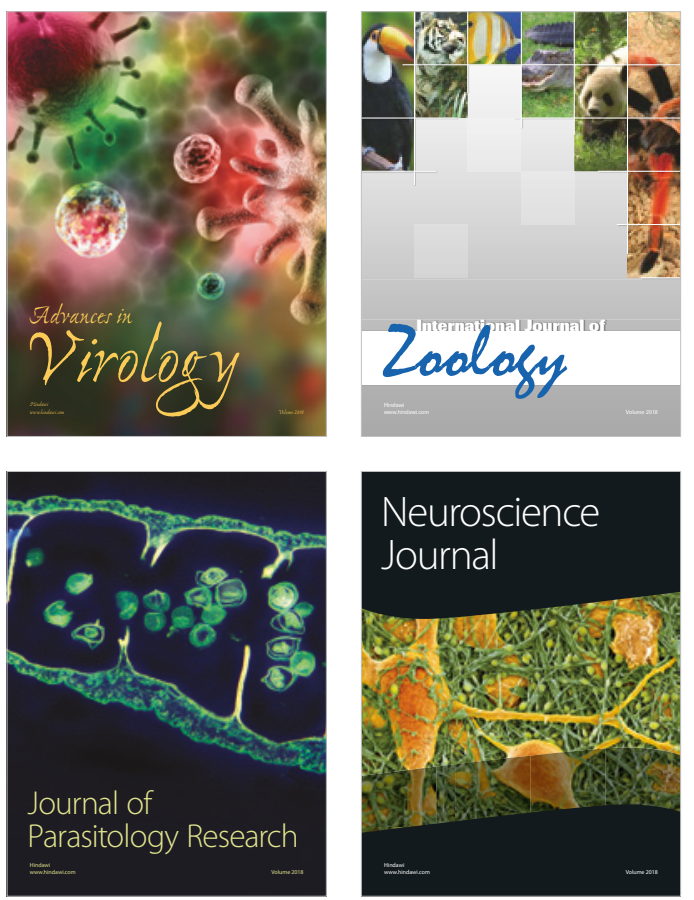
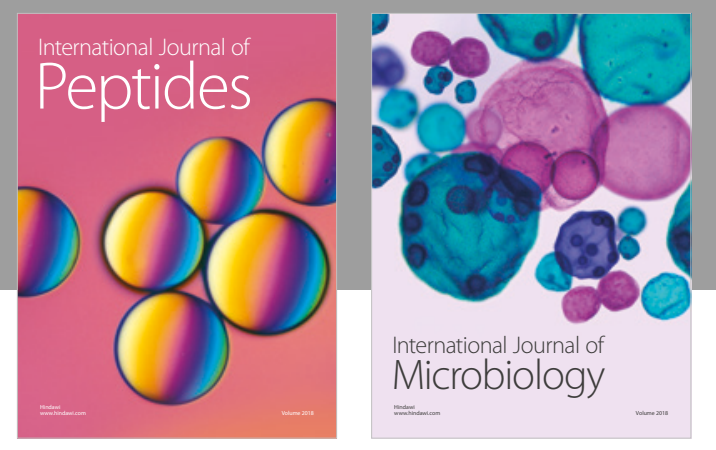

nternational Journal of Microbiology
Journal of
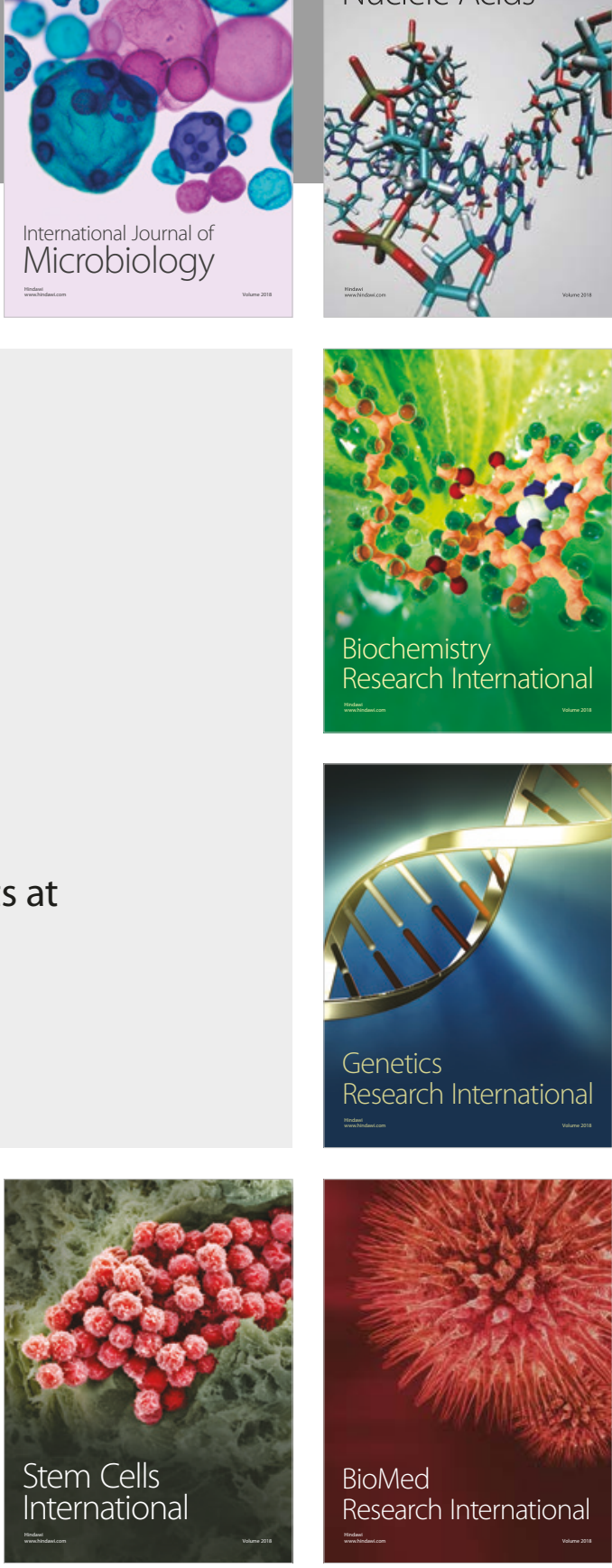
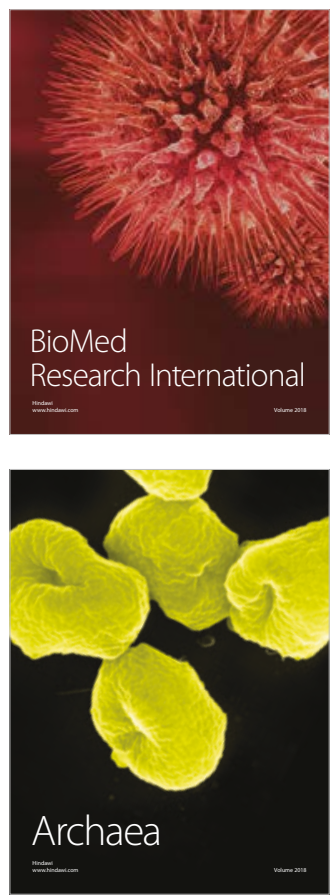